\title{
Patient with H syndrome, cardiogenic shock, multiorgan infiltration, and digital ischemia
}

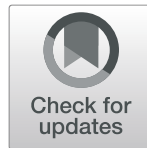

Laura Ventura-Espejo ${ }^{1}$, Inés Gracia-Darder², Silvia Escribá-Bori', Eva Regina Amador-González³, Ana Martín-Santiago ${ }^{2}$ and Jan Ramakers ${ }^{1,4^{*}}$ (i)

\begin{abstract}
Background: $\mathrm{H}$ syndrome (HS) is a rare autoinflammatory disease caused by a mutation in the solute carrier family 29, member 3 (SCL29A3) gene. It has a variable clinical presentation and little phenotype-genotype correlation. The pathognomonic sign of HS is cutaneous hyperpigmentation located mainly in the inner thighs and often accompanied by other systemic manifestations. Improvement after tocilizumab treatment has been reported in a few patients with HS. We report the first patient with HS who presented cardiogenic shock, multiorgan infiltration, and digital ischemia.
\end{abstract}

Case presentation: 8-year-old boy born to consanguineous parents of Moroccan origin who was admitted to the intensive care unit during the Coronavirus Disease-2019 (COVID-19) pandemic with tachypnoea, tachycardia, and oliguria.

Echocardiography showed dilated cardiomyopathy and severe systolic dysfunction compatible with cardiogenic shock. Additionally, he presented with multiple organ dysfunction syndrome. SARS-CoV-2 polymerase chain reaction (PCR) and antibody detection by chromatographic immunoassay were negative.

A previously ordered gene panel for pre-existing sensorineural hearing loss showed a pathological mutation in the SCL29A3 gene compatible with H syndrome.

Computed tomography scan revealed extensive alveolar infiltrates in the lungs and multiple poor defined hypodense lesions in liver, spleen, and kidneys; adenopathy; and cardiomegaly with left ventricle subendocardial nodules.

Invasive mechanical ventilation, broad antibiotic and antifungal coverage showed no significant response. Therefore, Tocilizumab as compassionate use together with pulsed intravenous methylprednisolone was initiated. Improvement was impressive leading to normalization of inflammation markers, liver and kidney function, and stabilising heart function. Two weeks later, he was discharged and has been clinically well since then on two weekly administration of Tocilizumab.

Conclusions: We report the most severe disease course produced by HS described so far in the literature. Our patient's manifestations included uncommon, new complications such as acute heart failure with severe systolic dysfunction, multi-organ cell infiltrate, and digital ischemia.

Most of the clinical symptoms of our patient could have been explained by SARS-CoV-2, demonstrating the

\footnotetext{
* Correspondence: jan.ramakers@ssib.es

${ }^{1}$ Paediatric Department, Hospital Universitario Son Espases, Carretera de Valldemosa, 79, 07120 Palma, Spain

${ }^{4}$ Multidisciplinary Group for Research in Peadiatrics. Hospital Universitari Son

Espases, Balearic Islands Health Research Institute (IdISBa), Carretera de

Valldemossa, 79, 07120 Palma, Spain

Full list of author information is available at the end of the article
}

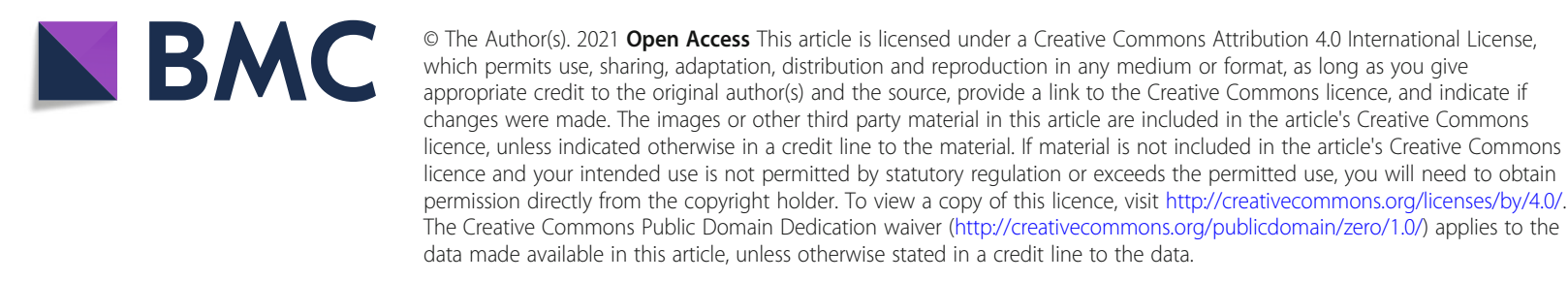


importance of a detailed differential diagnosis to ensure optimal treatment.

Although the mechanism of autoinflammation of HS remains uncertain, the good response of our patient to

Tocilizumab makes a case for the important role of IL-6 in this syndrome and for considering Tocilizumab as a first-

line treatment, at least in severely affected patients.

Keywords: $\mathrm{H}$ syndrome, Cardiogenic shock, Multiorgan infiltration, Digital ischemia, Paediatric intensive care unit, Interleukin-6, Tocilizumab, CT-scan, Case report

\section{Background}

HS (OMIM \#612391) is an autosomal recessive disorder caused by homozygous or compound heterozygous mutation in SLC29A3, the gene on chromosome 10q22 that encodes human equilibrative nucleoside transporter-3 (hENT3) [1].

HS was first described in 2008 in 6 consanguineous Arabic families [2]. Since then, around 100 cases have been reported [3-5]. The average age at onset is 9.7 years [6].

Previous studies have described other diseases caused by mutations in the SLC29A3 gene, such as pigmented hypertrichosis dermatosis with insulin-dependent diabetes syndrome (PHID), Faisalabad histiocytosis, and familial Rosai Dorfman disease, among others. Many patients shared overlapping signs and symptoms, leading to the suggestion that they should be regarded as the same entity [7-10].
The pathognomonic sign of HS is cutaneous hyperpigmentation located mainly in the inner thighs and often accompanied by hypertrichosis and progressive sclerodermatous induration. Other manifestations include histiocytosis, hepatosplenomegaly, heart anomalies, sensorineural hearing loss (SNHL), exophthalmos, endocrinopathy such as insulin-dependent diabetes mellitus (IDDM), genital abnormalities, and fixed flexion contractures of proximal interphalangeal joints $[2-4,7,11]$. Histologically, skin lesions show a perivascular dermal and subcutaneous infiltrate, composed mainly of histiocytes and plasma cells later replaced by fibrosis.

HS shows a high variability in clinical presentation with a lack of phenotype-genotype correlation even in siblings with identical mutations $[3,7,12]$.

We expand the clinical spectrum of HS describing the first patient who presented cardiogenic shock and multiorgan cell infiltrate.

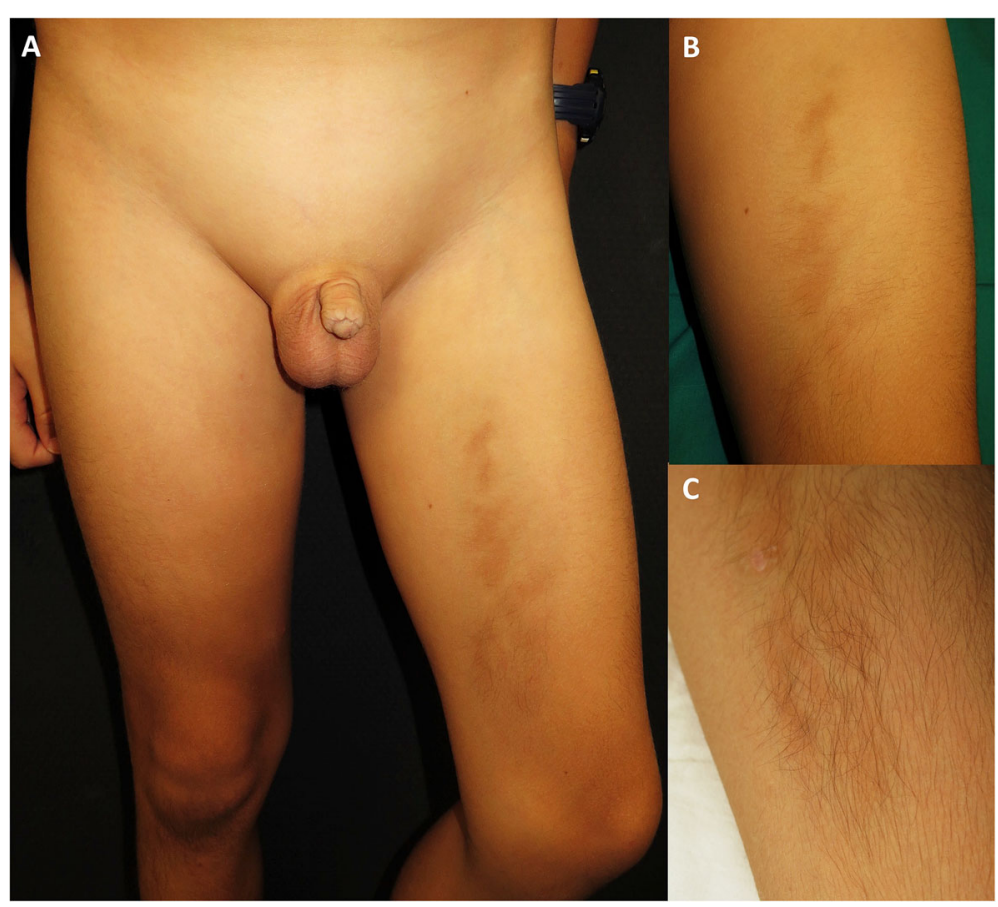

Fig. 1 A) Oedema of pubis and scrotum. B) Linear hyperpigmented and indurated plaque with poorly defined edges on the anterior medial aspect of the left thigh. C) Hypertrichosis on the distal region of the hyperpigmented plaque 


\section{Case presentation}

We report an 8-year-old boy born to consanguineous parents of Moroccan origin who was admitted to the intensive care unit because of dyspnoea, fever, and intense abdominal pain during the COVID-19pandemic. His medical history was positive for SNHL, diagnosed at five years of age, and a gene panel had recently been ordered for this reason. A few months previously, he had suffered an episode of Henoch-Schönlein purpura; and during a follow-up visit, a linear indurated patch was observed on the left thigh. His 4-year-old sister had been diagnosed with IDDM seven months before.

On admission, he showed tachypnoea, tachycardia, and oliguria. Physical exploration showed weak cardiac sounds, gallop rhythms, crackling, hypoventilation, and oedema of scrotum and mons pubis. The skin patch located on the inner left thigh had increased in size and showed thickening, in addition to hypertrichosis and hyperpigmentation (Fig. 1); histologically, the patch exhibited oedema with a lymphohistiocytic infiltrate in subcutaneous and perivascular cell tissue, but with no signs of thrombophlebitis or vasculitis (Fig. 2). Moreover, he developed purpuric lesions of ischemic aetiology in the 2nd and 3rd toes, similar to the lesions described in COVID-19 in children (Fig. 3). The echocardiography detected a dilated cardiomyopathy (left ventricle enddiastolic volume $54 \mathrm{~mm} \mathrm{Z}$-score+2,9), severe systolic dysfunction (30\% of left ventricular ejection fraction (LVEF)), mild diastolic dysfunction (fusion of E/A, E/E' 16) and elevated pulmonary arterial pressure (tricuspid regurgitation gradient $46 \mathrm{mmHg}$ ) confirming cardiogenic shock.

Acute phase reactants were raised, and hepatic and renal function markers were altered (Table 1). High levels of NT-proB-type natriuretic peptide $(>35,000 \mathrm{pg} /$ $\mathrm{mL})$, Renin $(4098 \mu \mathrm{U} / \mathrm{mL})$, and troponin I $(59.6 \mathrm{ng} / \mathrm{L})$ were in line with heart failure. Pharyngeal swab test was negative for SARS-CoV-2 and there was no history suggestive of COVID-19 in his family or immediate environment either. Antibody detection by chromatographic immunoassay during the acute phase and after 6 weeks were negative.

After detecting a mutation in the SCL29A3 gene (NM_018344.6:c.971C > T; (p.Pro324Leu)), described as pathological $[4,13]$ in the gene panel ordered for SNHL, the patient was diagnosed with HS, which was

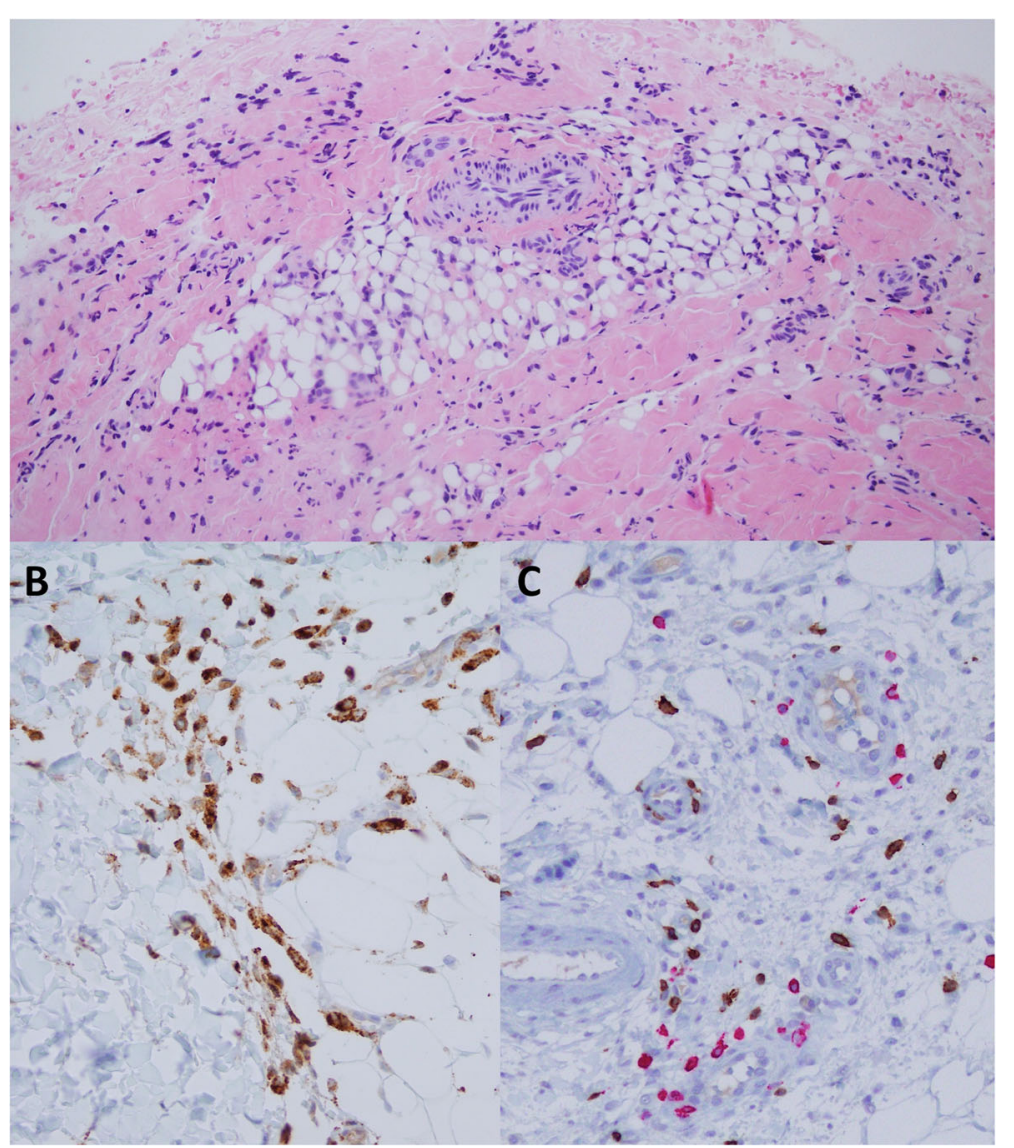

Fig. 2 A) Lymphohistiocytic inflammatory infiltrate with areas of lipoatrophy in subcutaneous tissue. B) Presence of histiocytes in the hypodermis (IHQ CD68 60x). C) Infiltrate contains CD3 (brownish) and CD20 (fuchsia) cells in equal proportion, 40x 


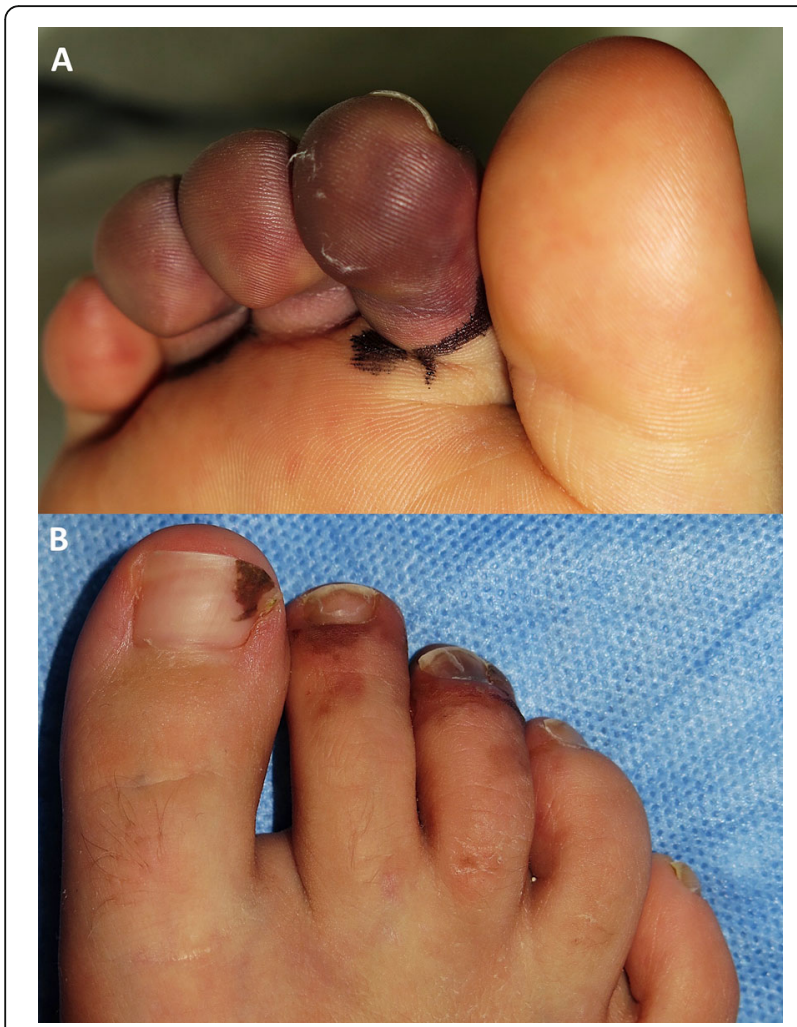

Fig. 3 Purpuric macules on the ventral and distal-dorsal side of the 2nd, 3rd, and partially 4th toes

compatible with his phenotype. Later on, because earlyonset IDDM is a typical feature of HS [3, 6, 12], a genetic panel was done to his sister and the same mutation was found.

Computed tomography scan showed extensive alveolar infiltrates in the lungs and multiple poor defined hypodense lesions in liver, spleen, and kidneys; adenopathy; and cardiomegaly with left ventricle subendocardial nodules. (Fig. 4) Tumour markers (neuron-specific enolase, alpha-fetoprotein, human chorionic gonadotropin), bone marrow biopsy, and serum amyloid A were normal. Pleural fluid, bronchial secretion, and skin biopsy revealed non-atypical lymphocytic infiltration.

Invasive mechanical ventilation was started, and a pleura drainage tube was placed, together with broad antibiotic and antifungal coverage. After 4 days without significant improvement, Tocilizumab $(8 \mathrm{mg} / \mathrm{kg})$ and pulsed intravenous methylprednisolone $(500 \mathrm{mg}$ three consecutive days) were initiated. Improvement within a few days was impressive: mechanical ventilation could be stopped, inflammation markers and liver and kidney function normalized, heart function stabilized, achieving $50 \%$ of LVEF. Two weeks later, he was able to be discharged and has been clinically well and stable since then, only with administration of Tocilizumab every two weeks. A control CT scan done 10 weeks later showed complete resolution of previous abnormalities (Fig. 5).

\section{Discussion}

To the best of our knowledge, this is the first case of HS reported in the literature presenting with acute cardiogenic shock; although two patients have been described with progressive heart failure during the course of the disease $[14,15]$. Previous studies have shown that the spectrum of cardiac involvement in HS is widely diversified: mild pulmonary stenosis, pericardial effusion, pulmonary hypertension, ductus arteriosus with right to left shunt, atrial and ventricular septal defects, mitral valve prolapse, cardiomegaly, and myocardial hypertrophy [1, $16,17]$. The persistence of the left superior vena cava, as in our patient, has also been described previously [5].

It has been hypothesized that the expression of mutant hENT3 in the heart, affecting nucleoside transport activity, could interfere with normal cardiac activities and morphogenesis [4].

Our patient showed diffuse multiorgan infiltration in liver, spleen, lungs, and kidneys on a whole-body CT scan. (Fig. 4) Similar findings were described in another patient, although they were limited to bone marrow only and, as such, macrophage proliferation was postulated as the cause [10]. Extensive infiltration of multiple organs, possibly affecting the heart as well, as shown by the subendocardial nodules, has not been described previously and might represent severe disease activity leading to the acute life-threatening presentation. However, in our patient, bone marrow biopsy was normal, and another organ biopsy was not performed.

Table 1 Laboratory values (with normal values) of our patient over time

\begin{tabular}{|c|c|c|c|c|c|c|c|c|c|}
\hline \multicolumn{2}{|c|}{ Laboratory values } & \multirow{2}{*}{$\begin{array}{c}1 \text { st Day } \\
03 / 03 / 20\end{array}$} & \multirow{2}{*}{$\begin{array}{l}\text { 2nd Day } \\
04 / 03 / 20\end{array}$} & \multirow{2}{*}{$\begin{array}{l}\text { 3th Day } \\
05 / 03 / 20\end{array}$} & \multirow{2}{*}{$\begin{array}{l}\text { 4th Day } \\
06 / 03 / 20\end{array}$} & \multirow{2}{*}{$\begin{array}{l}\text { 6th Day } \\
08 / 03 / 20\end{array}$} & \multirow{2}{*}{$\begin{array}{l}\text { 8th Day } \\
10 / 03 / 20\end{array}$} & \multirow{2}{*}{$\begin{array}{l}\text { 15th Day } \\
17 / 03 / 2020\end{array}$} & \multirow{2}{*}{$\begin{array}{c}2 \text { weeks after } \\
\text { hospital discharge } \\
17 / 04 / 2020\end{array}$} \\
\hline Date & Normal values & & & & & & & & \\
\hline $\operatorname{AST}(U / L)$ & $18-36$ & 303 & & 108 & & & & & 22 \\
\hline $\operatorname{ALT}(U / L)$ & $09-25$ & 641 & 433 & 304 & & 91 & 65 & 81 & 25 \\
\hline NT-PROBNP $(\mathrm{pg} / \mathrm{mL})$ & $0-157$ & $>35000$ & & & & & & 5919 & 256 \\
\hline Troponin I (ng/L) & $0,0-34,0(p 99)$ & 59,6 & & 25,4 & & & 20 & 24,6 & \\
\hline $\mathrm{LDH}(\mathrm{U} / \mathrm{L})$ & $192-321$ & 576 & 474 & 519 & $i v^{n}$ & 272 & 257 & 219 & \\
\hline C-reactive Protein $(\mathrm{mg} / \mathrm{dL}$ ) & $0,0-0,5$ & 7,51 & 8,71 & 11,84 & ko" & 1,29 & 0,42 & 0,08 & 0,02 \\
\hline Procalcitonin $(\mathrm{ng} / \mathrm{mL})$ & $0,00-0,07$ & 4,5 & & 2,51 & & & & 0,11 & \\
\hline $\operatorname{Renin}(\mu \mathrm{U} / \mathrm{mL})$ & $2,8-39,9$ & 4098 & & & & & 54 & & \\
\hline
\end{tabular}




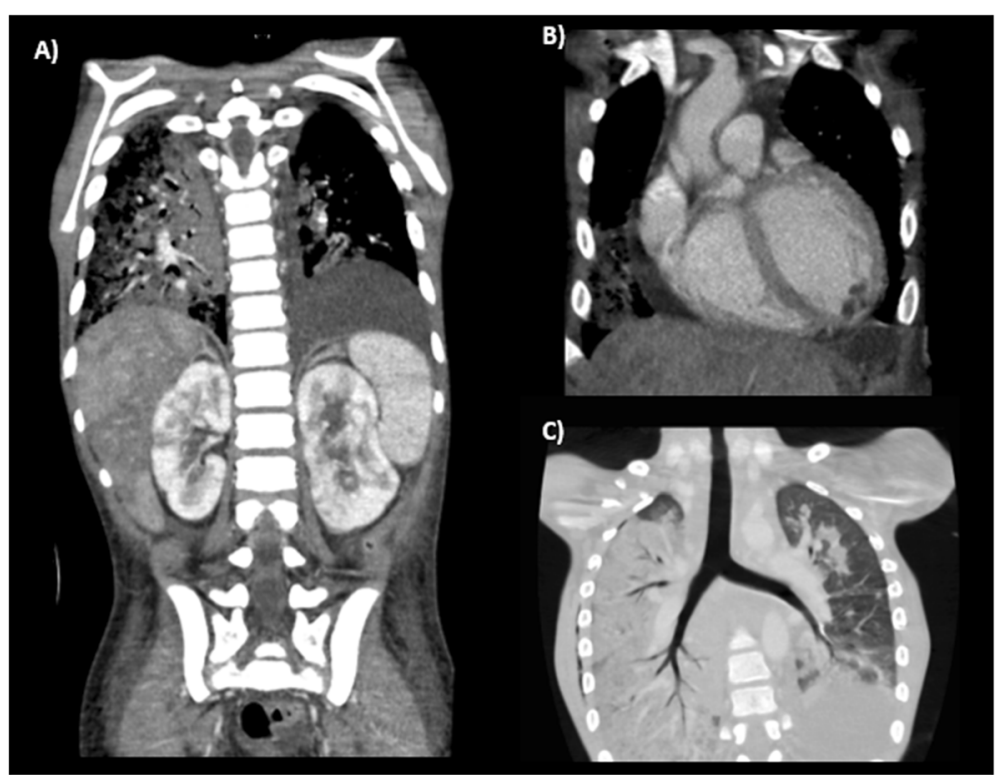

Fig. 4 Coronal contrast-enhanced CT of the chest and abdomen. A and B) Soft tissue, and C) Lung algorithm. Images show extensive alveolar infiltrates with hepatisation of both lungs and moderate left pleural effusion. Diffuse cardiomegaly and hypovascular nodules located in septal and left apical ventricular subendocardium. Multiple ill-defined hypodense lesions predominantly involving the periphery of the liver, kidneys, and spleen. Enlarged mediastinal lymph nodes were also present (not shown)

Two months after starting Tocilizumab, a control lung CT scan and abdominal MRI (Fig. 5) were normal without any signs of multiorgan infiltration. Therefore, the rapid improvement after initiation of treatment would be suggestive of a transient cell infiltrate as the underlying cause of the initial imaging findings.

The patient presented purpuric lesions from the 2nd to the 4th toes, suggesting a thrombotic or embolic aetiology in the context of his cardiomyopathy and severe autoinflammatory syndrome. As far as we know, digital ischemia has not been described in HS; although similar acral ischemic lesions have been described in severely ill patients during the COVID-19 outbreak [18]. Nonetheless, SARS-CoV-2 polymerase chain reaction (PCR) during the acute phase, and antibody detection by chromatographic immunoassay during the acute phase and after 6 weeks were negative.

As we mentioned before, we found the same mutation in her sister. This lack of phenotype-genotype correlation, even in siblings with identical mutations, had been already described in other case reports $[3,7,12]$. It highlights the importance of knowing the different diagnostic features of this disease to make an early-diagnosis and possibly preventing long-term complications.

hENT3 is critical for nucleotide synthesis by maintaining lysosome integrity. Thus, hENT3 deficiency affects apoptotic cell clearance and can increase macrophage colony-stimulating factor (MCSF) signalling. MCSF

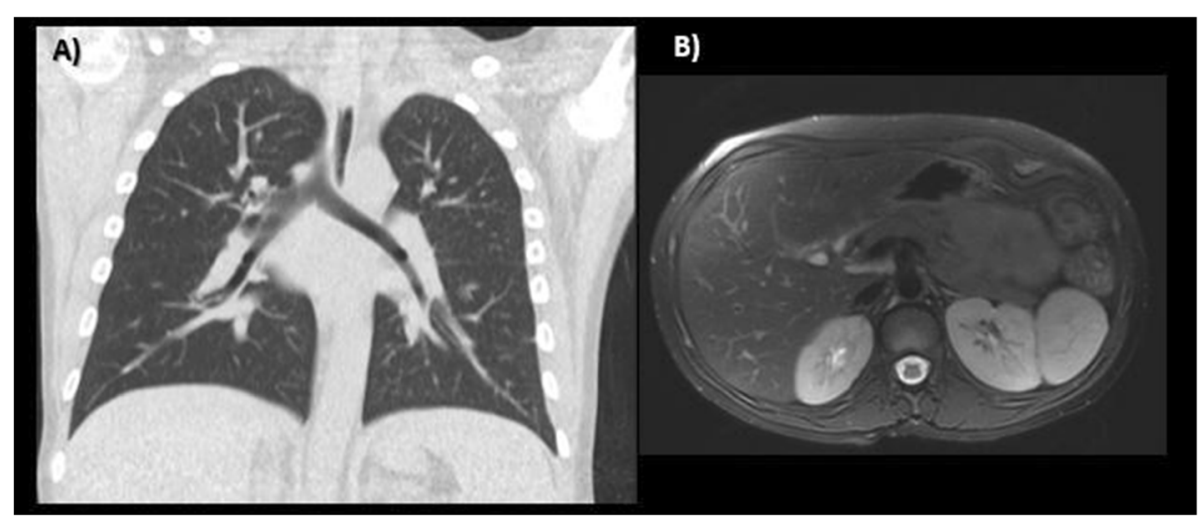

Fig. 5 Complete resolution of pulmonary and abdominal viscera infiltrates is seen in A) Coronal non-enhanced lung CT, and B) Axial FS T2WI MRI 
enhances macrophage and histiocyte proliferation but alters their function, with macrophage infiltration observed in multiple organs of animals with ENT3 deficiency $[19,20]$. This contributes to elevated cytokine excretion and the immune response, resulting in skin sclerosis and hypertrichosis [11]. In this way, therapeutic benefit could be suggested for anti-cytokine biologicals. However, several of these treatments have not been effective, with various studies showing poor response to anti IL-1 or TNF-alpha treatment, despite high serum levels of IL-1 and TNF [3, 10, 13, 16, 21, 22]. Similarly, Mistry et al. reported a patient with no clinical response, but with c-reactive protein normalization after Tocilizumab treatment [23].

Our patient showed a very good response, in line with recent reports on successful treatment with intravenous Tocilizumab [3, 21].

Interestingly, interleukin-6 also plays an important role in cytokine release syndrome of COVID-19 [24]. Our patient had tested negative for COVID19. However, we cannot completely rule out COVID19 as an aggravating factor in this HS, as false negative PCRs and serologies have been reported [25].

\section{Conclusions}

We report the most severe disease course produced by HS described so far in the literature. Our patient's manifestations included uncommon, new complications such as acute heart failure with severe systolic dysfunction, multi-organ infiltration, and digital ischemia.

Most of the clinical symptoms of our patient could have been explained by SARS-CoV-2, demonstrating the importance of a detailed differential diagnosis to ensure optimal treatment.

Although the mechanism of autoinflammation of HS remains uncertain, the good response of our patient to Tocilizumab makes a case for the important role of IL-6 in this syndrome and for Tocilizumab as a first-line treatment, at least in severely affected patients.

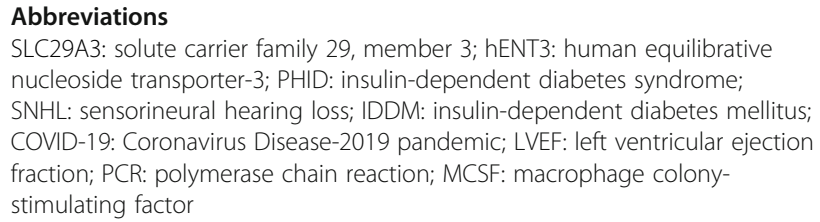

\section{Acknowledgements}

Not applicable.

\section{Authors' contributions}

LV assisted the patient in the intensive care unit, looked for the literature regarding $\mathrm{H}$ Syndrome, was a major contributor in writing the manuscript, contacted to the Ethic Commit and asked for the consent to the patient's family. IG took pictures of the dermatology findings, improve the data in the manuscript that described dermatology and histology findings and suggested some articles to support these. AG examined the dermatology data wrote by IG and suggest some improvement of the original draft manuscript. EA contributed the scanned images, interpreted them and helped with their description in the manuscript. SE contributed the echocardiographic images, interpreted them and helped with their description and interpretation in the manuscript. JR assisted the patient during hospital stay and out-patient follow up, revised the literature used, was the second contributor in writing the manuscript, helped to contact to the Ethic Commit and surveyed the final manuscript.

\section{Funding}

We thank the Balearic Islands Health Research Institute (IdISBa) for funding the article processing charge.

Availability of data and materials

All data generated or analysed during this study are included in this published article.

\section{Declarations}

Ethics approval and consent to participate

Ethics approval was obtained according to local protocols.

Consent for publication

Consent for publication was obtain from the parents of the child.

\section{Competing interests}

The authors declare that they have no competing interests.

\section{Author details}

${ }^{1}$ Paediatric Department, Hospital Universitario Son Espases, Carretera de Valldemosa, 79, 07120 Palma, Spain. ²Dermatology Department, Hospital Universitario Son Espases, Palma, Spain. ${ }^{3}$ Paediatric Radiology Department, Hospital Universitario Son Espases, Palma, Spain. ${ }^{4}$ Multidisciplinary Group for Research in Peadiatrics. Hospital Universitari Son Espases, Balearic Islands Health Research Institute (IdISBa), Carretera de Valldemossa, 79, 07120 Palma, Spain.

Received: 14 December 2020 Accepted: 5 April 2021

Published online: 30 June 2021

References

1. Molho-Pessach V, Lerer I, Abeliovich D, Agha Z, Abu Libdeh A, Broshtilova V, et al. The $\mathrm{H}$ syndrome is caused by mutations in the nucleoside transporter hENT3. Am J Hum Genet. 2008;83(4):529-34. https://doi.org/10.1016/j.ajhg.2 008.09.013.

2. Molho-Pessach V, Agha Z, Aamar S, Glaser B, Doviner V, Hiller N, et al. The H syndrome: a genodermatosis characterized by indurated, hyperpigmented, and hypertrichotic skin with systemic manifestations. J Am Acad Dermatol. 2008; [cited 2020 Apr 19];59(1):79-85. Available from: http://www.ncbi.nlm. nih.gov/pubmed/18410979, https://doi.org/10.1016/j.jaad.2008.03.021.

3. Bloom JL, Lin C, Imundo L, Guthery S, Stepenaskie S, Galambos C, et al. H syndrome: 5 new cases from the United States with novel features and responses to therapy. Pediatr Rheumatol. 2017;15(1):1-12.

4. Jaouadi H, Zaouak A, Sellami K, Messaoud O, Chargui M, Hammami H, et al. $\mathrm{H}$ syndrome: clinical, histological and genetic investigation in Tunisian patients. J Dermatol. 2018;45(8):978-85. https://doi.org/10.1111/1346-813 8.14359 .

5. Vural S, Ertop P, Durmaz CD, Sanll H, Okçu Heper A, Kundakçl N, et al. Skindominant phenotype in a patient with $\mathrm{H}$ syndrome: identification of a novel mutation in the SLC29A3 gene. Cytogenet Genome Res. 2017;151(4): 186-90. https://doi.org/10.1159/000475908.

6. Abarca Barriga HH, Trubnykova M, Polar Córdoba V, Ramos Diaz KJ, Aviles AN. Síndrome H: primer caso pediátrico reportado en América Latina. Rev Chil Pediatr. 2016;87(6):494-9. Available from:. https://doi.org/10.1016/j. rchipe.2016.03.006

7. Al-Haggar M, Salem N, Wahba Y, Ahmad N, Jonard L, Abdel-Hady D, et al. Novel homozygous SLC29A3 mutations among two unrelated Egyptian families with spectral features of H-syndrome. Pediatr Diabetes. 2015;16(4): 305-16. https://doi.org/10.1111/pedi.12160.

8. Rafiq NK, Hussain K, Brogan PA. Tocilizumab for the Treatment of SLC29A3 Mutation Positive PHID Syndrome. Pediatrics. 2017;140(5):e20163148. https:// doi.org/10.1542/peds.2016-3148. 
9. De Jesus J, Imane Z, Senée V, Romero S, Guillausseau PJ, Balafrej A, et al. SLC29A3 mutation in a patient with syndromic diabetes with features of pigmented hypertrichotic dermatosis with insulin-dependent diabetes, $H$ syndrome and Faisalabad histiocytosis. Diabetes Metab. 2013;39(3):281-5. Available from:. https://doi.org/10.1016/j.diabet.2013.03.007.

10. Melki I, Lambot K, Jonard L, Couloigner V, Quartier P, Neven B, BaderMeunier B. Mutation in the SLC29A3 gene: a new cause of a monogenic, autoinflammatory condition. Pediatrics. 2013;131(4):e1308-13. https://doi. org/10.1542/peds.2012-2255. Epub 2013 Mar 25.

11. Liu JW, Si N, Wang LQ, Shen T, Zeng XJ, Zhang $X$, et al. Identification of a novel mutation in solute carrier family 29, member 3 in a Chinese patient with H syndrome. Chin Med J. 2015;128(10):1336-9. https://doi.org/10.4103/ 0366-6999.156778.

12. Tekin B, Atay Z, Ergun T, Can M, Tuney D, Babay S, et al. H syndrome: a multifaceted histiocytic disorder with hyperpigmentation and hypertrichosis. Acta Derm Venereol. 2015;95(8):1021-3. https://doi.org/10.2340/0001 5555-2145.

13. Molho-Pessach V, Ramot Y, Camille F, Doviner V, Babay S, Luis SJ, et al. H syndrome: The first 79 patients. J Am Acad Dermatol. 2014;70(1):80-8. Available from:. https://doi.org/10.1016/j.jaad.2013.09.019.

14. Deshpande R, Parthasarathy L, Dalal A, Khadilkar V, Khadilkar A. Variability in the manifestations and evolution of symptoms in a patient with $\mathrm{H}$ syndrome. Indian J Pediatr. 2016;83(1):92-3. https://doi.org/10.1007/s12098015-1776-5.

15. Shankarappa RK, Ananthakrishna R, Math RS, Yalagudri SD, Karur S, Dwarakaprasad R, Nanjappa MC, Molho-Pessach V. Accelerated coronary atherosclerosis and H syndrome. BMJ Case Rep. 2011;2011:bcr0320114019. https://doi.org/10.1136/bcr.03.2011.4019.

16. Senniappan S, Hughes M, Shah P, Shah V, Kaski JP, Brogan $P$, et al. Pigmentary hypertrichosis and non-autoimmune insulin-dependent diabetes mellitus (PHID) syndrome is associated with severe chronic inflammation and cardiomyopathy, and represents a new monogenic autoinflammatory syndrome. J Pediatr Endocrinol Metab. 2013;26(9-10): 877-82. https://doi.org/10.1515/jpem-2013-0062.

17. Molho-Pessach V, Agha Z, Aamar S, Glaser B, Doviner V, Hiller N, et al. The H syndrome: a genodermatosis characterized by indurated, hyperpigmented, and hypertrichotic skin with systemic manifestations. J Am Acad Dermatol. 2008:59(1):79-85. https://doi.org/10.1016/j.jaad.2008.03.021.

18. Galván Casas C, Català A, Carretero Hernández G, Rodríguez-Jiménez P, Fernández Nieto D, Rodríguez-Villa Lario A, et al. Classification of the cutaneous manifestations of COVID-19: a rapid prospective nationwide consensus study in Spain with 375 cases. Br J Dermatol. 2020:0-3 Available from: http://www.ncbi.nlm.nih.gov/pubmed/32348545, https://doi.org/1 $0.1111 /$ bjd. 19163.

19. Kang N, Jun AH, Bhutia YD, Kannan N, Unadkat JD, Govindarajan R. Human equilibrative nucleoside transporter-3 (hENT3) spectrum disorder mutations impair nucleoside transport, protein localization, and stability. J Biol Chem. 2010;285(36):28343-52. https://doi.org/10.1074/jbc.M110.109199.

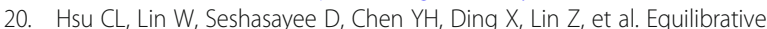
nucleoside transporter 3 deficiency perturbs lysosome function and macrophage homeostasis. Science (80-). 2012; [cited 2021 Feb 25];335(6064): 89-92. Available from: https://science.sciencemag.org/content/335/6064/ 89, https://doi.org/10.1126/science.1213682.

21. Morgan NV, Morris MR, Cangul H, Gleeson D, Straatman-Iwanowska A, Davies N, Keenan S, Pasha S, Rahman F, Gentle D, Vreeswijk MP, Devilee P, Knowles MA, Ceylaner S, Trembath RC, Dalence C, Kismet E, Köseoğlu V, Rossbach HC, Gissen P, Tannahill D, Maher ER. Mutations in SLC29A3, encoding an equilibrative nucleoside transporter ENT3, cause a familial histiocytosis syndrome (Faisalabad histiocytosis) and familial Rosai-Dorfman disease. PLoS Genet. 2010;6(2):e1000833. https://doi.org/10.1371/journal. pgen.1000833

22. Çağdaş D, Sürücü N, Tan Ç, Kayaoğlu B, Özgül RK, Akkaya-Ulum YZ, et al. Autoinflammation in addition to combined immunodeficiency: SLC29A3 gene defect. Mol Immunol. 2020;121(February):28-37. https://doi.org/10.101 6/j.molimm.2020.02.014.

23. Mistry A, Parry D, Matthews B, Laws P, Goodfield M, Savic S. A case of SLC29A3 Spectrum disorder-unresponsive to multiple immunomodulatory therapies. J Clin Immunol. 2016;36(5):429-33. https://doi.org/10.1007/s10875016-0301-6.

24. Sciascia S, Aprà F, Baffa A, Baldovino S, Boaro D, Boero R, et al. Pilot prospective open, single-arm multicentre study on off-label use of tocilizumab in patients with severe COVID-19. Clin Exp Rheumatol. 2020:1-4 Available from: http://www.ncbi.nlm.nih.gov/pubmed/32359035.

25. Ai T, Yang Z, Hou H, Zhan C, Chen C, Lv W, et al. Correlation of chest CT and RT-PCR testing in coronavirus disease 2019 (COVID-19) in China: a report of 1014 cases. Radiology. 2019;2020:200642.

\section{Publisher's Note}

Springer Nature remains neutral with regard to jurisdictional claims in published maps and institutional affiliations.

\section{Ready to submit your research? Choose BMC and benefit from:}

- fast, convenient online submission

- thorough peer review by experienced researchers in your field

- rapid publication on acceptance

- support for research data, including large and complex data types

- gold Open Access which fosters wider collaboration and increased citations

- maximum visibility for your research: over $100 \mathrm{M}$ website views per year

At BMC, research is always in progress.

Learn more biomedcentral.com/submissions 